\title{
A "domino-effect" case of multiple ocular pathologies ascribed to various complex causes
}

\author{
Ricarda M. Konder, BSc' and Erin Demmings, BScH, MEd, MD, FRCSC2 \\ I. Class of 2020, Faculty of Medicine, Dalhousie University, Saint John, New Brunswick, Canada. \\ 2. Department of Ophthalmology and Visual Sciences, Dalhousie University, Saint John, New Brunswick, Canada.
}

\begin{abstract}
This is a learning case targeted at medical students and other healthcare professionals who wish to improve their understanding of ophthalmic conditions and their anatomical underpinnings. This report will introduce a patient with a complex history of ocular pathologies who presented to a small urban community ophthalmology clinic. A brief summary of past medical history will be presented, followed by a detailed explanation of the symptoms, etiologies, and chosen treatments for the patient's various conditions (iris and chorioretinal colobomas, uveitis, cataracts, retinal detachments, corneal edema, and glaucoma). In this case, the various medical interventions for our patient's initial problems often led to complications and exacerbations of pre-existing conditions; therefore, special attention will be paid to highlighting both the pathophysiological and mechanical influences that may lead to, and exacerbate, eye disease.
\end{abstract}

\section{Patient History and General Information}

A 56-year-old woman presented to our clinic with the chief complaint of bright flashes in the superonasal field of vision of her right eye over four days.

Her history was significant for various ocular problems (Figure 1). She had bilateral congenital chorioretinal colobomas as well as an iris coloboma in the right eye. She previously underwent left cataract surgery and soon after had a left retinal detachment which was corrected surgically (year 1). A second cataract surgery, which was combined with a pupilloplasty to close the iris coloboma, followed in her right eye several years later (year 4). This led to right chronic anterior uveitis. At the time of her first visit in our clinic (year 10), she reported taking topical ketorolac (Acular) twice a day to the right eye and lubricating drops bilaterally as needed. She denied any family history of ocular disease.

Past medical history was significant for premature birth, gastro-esophageal reflux disease (GERD), and a pulmonary embolus with a secondary gastrointestinal bleed from anticoagulation. At the time she presented, she reported taking rivaroxaban (Xarelto) and pantoprazole (Protonix). She denied any allergies.

\section{Pathophysiologies in Relation to Eye Anatomy \\ Coloboma}

Our patient had known bilateral congenital colobomas. A coloboma is an incompletely formed structure or tissue in the eye, and it often manifests as a hole in the iris, retina, choroid, or optic nerve (refer to Figure 2 for the basic anatomical structures). The cause of this phenomenon is the improper closure of an embryological structure called the choroidal fissure; if not properly closed by week 5 of gestation, colobomas can manifest in the various aforementioned presentations. ${ }^{1}$ Our patient had colobomas in her irises (the coloured parts of the eye which modify the size of the pupil to optimize the amount of light entering the eye) as well as the retina (the neural tissue lining the back of the eye onto which light is projected by the

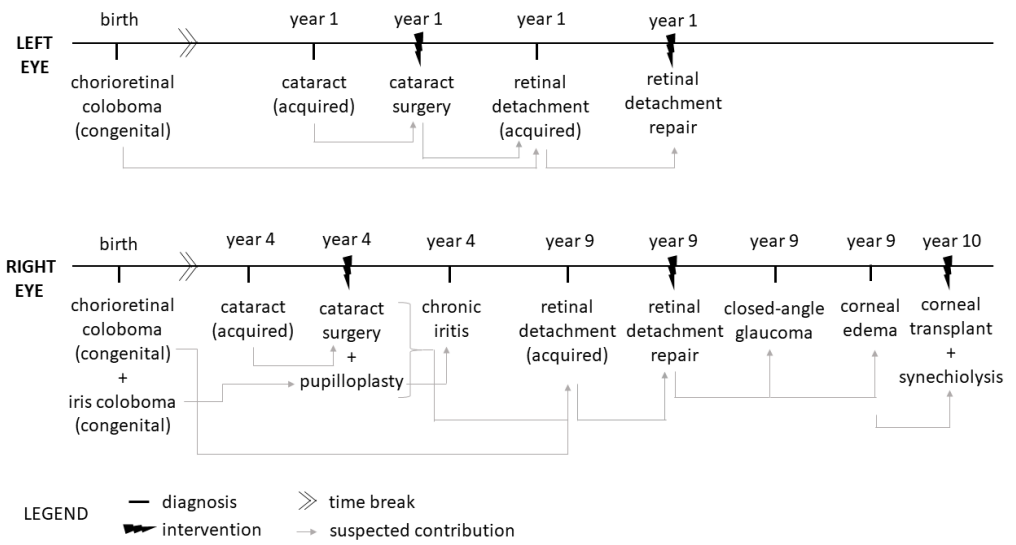

Figure I: Flowchart depicting our patient's ophthalmic conditions and surgical interventions (numbered years are used in lieu of specific years in order to protect patient confidentiality). Arrows indicate suspected contribution.

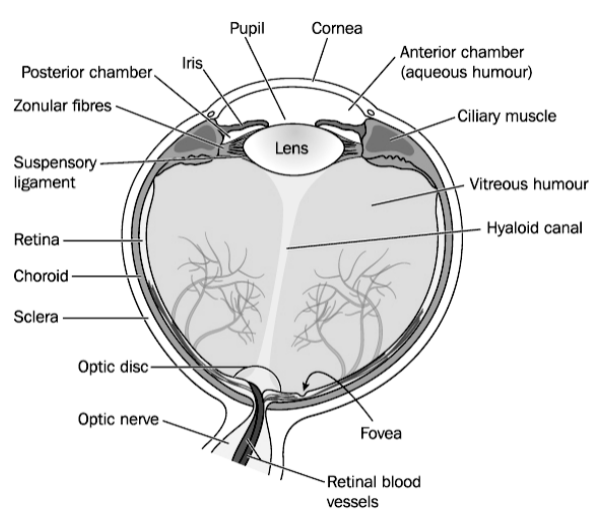

Figure 2: Overview of the main anatomical structures in the human eye in transverse crosssection. (Blamb/Shutterstock.com) 
crystalline lens situated behind the pupil).

In the iris, colobomas are normally only cosmetically symptomatic, but can cause visual glare in some patients. ${ }^{1}$ Our patient did opt for a right pupilloplasty (at the time of cataract surgery) in which the defect in the pupil was surgically closed (year 4). On top of her iris coloboma, she also had retinal colobomas, which are often more prone to causing visual problems, especially when affecting the macula. ${ }^{1}$ The macula is an area in the retina in which there is a very high concentration of photoreceptors named cones; the accumulation of these allows for crisp central vision. ${ }^{2}$ Fortunately, our patient's chorioretinal colobomas were not found at the site of the macula, meaning that she did not have major visual problems as a result of these malformations.

\section{Uveitis}

Aside from colobomas, the patient also suffered from chronic uveitis of the right eye. Uveitis is the inflammation of the uvea (a combination of the iris, the ciliary body, and the choroid, a pigmented layer underneath the external white sclera of the eyeball), and it can often present secondary to infections, systemic inflammatory disease, or trauma to the eye. ${ }^{3}$ Our patient suffered from anterior uveitis, meaning that the inflammation was limited to anterior ocular structures, normally the iris. Therefore, anterior uveitis is often referred to as iritis. ${ }^{3}$ As a result of her persistent iritis, our patient suffered from eye pain, redness, and photophobia. Her symptoms were managed with topical anti-inflammatories.

\section{Cataracts}

A cataract is a clouding of the crystalline lens which normally focuses the light onto its proper place on the retina. While cataracts can be caused by various factors such as UV radiation, trauma, diabetes mellitus, drugs, or hypertension, most are idiopathic or multifactorial. ${ }^{4}$ Generally speaking, cataracts are extremely common and are often a normal by-product of aging. In this particular patient, no singular cause for either cataract could be determined. At the onset of her left cataract (year 1), she was suffering from progressive left visual loss and therefore opted to have the lens extracted.

During cataract surgery, an incision is made at the corneal border to allow for access to the cloudy lens. The lens is then broken into smaller pieces, both mechanically and by ultrasonic energy. It is simultaneously aspirated out of the eye. ${ }^{5}$ In the place of the natural lens, a lens implant is placed with a refractive power appropriate for the patient's vision. After the patient's first cataract surgery (year 1), she experienced a retinal detachment involving her central vision for which she soon required a surgical correction.

\section{Retinal detachment}

A retinal detachment is the literal separation of the neurosensory retina from the retinal pigment epithelium in the posterior eye. Risk factors include extreme nearsightedness (myopia), aging, family history, or eye trauma including surgery and is an urgent problem that can result in significant vision loss if not promptly corrected. ${ }^{6}$ Chorioretinal colobomas are also a risk factor for retinal detachments. Often, patients will complain of an abrupt increase in bright flashes of light in the affected eye as well as an increase in floaters, which are small black or transparent specks in the field of vision. The patient had her retina re-attached via diathermy, a form of electrically induced heat that facilitates the re-adhesion of separated ocular tissues, and laser photocoagulation, a cauterization of small blood vessels in the eye. ${ }^{7}$ This intervention was uneventful.

This brings us to her first visit to our clinic (year 9) when she presented with bright flashes of light suggestive of yet another retinal detachment, but this time in her right eye. A primary assessment revealed visual acuities of 20/25-2 (right) and 20/50 (left). There was no improvement with pinholes, suggestive of a problem that cannot be fixed simply with corrective lenses. Intraocular pressure (IOP) was normal in the left eye $(17 \mathrm{mmHg}$ ) and slightly elevated in the right eye (23 $\mathrm{mmHg}$ ). On detailed examination, an area suspicious for a shallow retinal detachment was noted. This led to an immediate referral to a retina specialist for a surgical assessment.

Retinal detachment was confirmed with a B-scan ultrasound of the right eye. This warranted surgical repair including a right pars plana posterior vitrectomy. Intra-operatively, visualization of the retina was difficult because of the small pupil (from the previous pupilloplasty) as well as opacification of the lens capsule. The pupilloplasty was reversed by removing the stitches in order to facilitate a larger pupil and better visualization of the retina. The intraocular lens was removed as part of her complicated retinal detachment repair. The rest of the procedure was uneventful, and the retina was reattached.

\section{Bullous keratopathy secondary to corneal edema}

Following this surgery, the patient experienced right corneal edema. Corneal edema is the buildup of fluid within the cornea, the most anterior portion of the eye responsible for refracting light at an angle appropriate to facilitate its entry into the pupil. ${ }^{8}$ Edema can cause the cornea, a usually clear and transparent structure, to swell, leading to significant cloudiness in vision. Normally, the endothelial layer of the cornea is responsible for pumping out fluid, but in this case, it no longer functioned properly. ${ }^{8}$ Endothelial loss can be secondary to age, disease, or surgical trauma; given 
her extensive surgical history, the latter was likely her cause. Her edema progressed, causing the deposition of small vesicles within the cornea, known as bullous keratopathy, further exacerbating her vision loss and causing significant pain.

During a follow-up visit after her right retinal surgery, her central corneal thickness was measured to be 863 micrometres, whereas a normal thickness is around 520 micrometres. ${ }^{9}$ Her right visual acuity was 20/1000. Additionally, she was aphakic (without a lens due to the surgery), causing extreme farsightedness in this eye. With no lens, light entering the pupil can no longer be properly focused onto the retina. Since the damage to her cornea was persistent, she was referred to a cornea specialist for assessment and treatment. In a corneal transplant procedure called a penetrating keratoplasty, all five layers of the cornea were trephined and removed. A corneal graft from a post-mortem donor was subsequently inserted and secured using sutures..$^{10}$ The surgery was uneventful, and the patient was able to return home the next day.

\section{Glaucoma}

In addition to her corneal problems, our patient also developed elevated IOP in her right eye following her retinal detachment repair. Glaucoma is a disease causing characteristic optic neuropathy, usually from an increase in intraocular pressure. In this patient's case, her glaucoma (more specifically closed-angle glaucoma, which usually results from a rapid increase in IOP) was a post-operative complication of her retinal detachment. This was because, as part of her retinal detachment repair, a gas bubble was placed in front of the retina. Because no lens was present, this bubble expanded anteriorly and began to press on the iris, closing the natural outflow in the irideocorneal angle of the eye, and adhesions formed. She was treated initially with anti-glaucoma drops and then with surgical synechiolysis, which broke the adhesions.

\section{Current State}

On the date of last follow-up in our clinic (year 10), acuity in the right eye was 20/250 (corrected with pinhole to 20/60) and 20/50 in the left (corrected with pinhole to 20/40). Overall, she is doing well and her vision is slowly improving. She is still healing from her corneal transplant and sutures are being removed. Visual rehabilitation in the future may be achieved using a specialized scleral contact lens on the right, although surgical implantation of a new intraocular lens has not been ruled out.

\section{Conclusion}

This case demonstrates how ocular pathology as well as individual treatments can induce varying degrees of ocular disease. As depicted in Figure 1, multiple causes and pre-existing conditions led to the development of both of her retinal detachments, just like many of her surgical interventions led to various downstream effects. This highlights the multifactorial and highly complex nature of eye disease.

\section{Acknowledgments}

The authors would like to thank the patient for not only allowing the use of her data for the purpose of this learning case, but also for her unwavering optimism in light of the many difficult medical challenges that have come her way. Furthermore, they would like to thank ophthalmic technicians Sandra McIntyre and Sherry Bamford for their continued assistance in providing the best care environment for our patient and for enriching the educational experience for medical students on elective in this clinic.

The authors would like to emphasize that the patient gave explicit, informed consent, both verbally and in writing, for the use of her data in this learning case.

\section{References}

1. Skuta GL, Cantor LB, Weiss JS, Cibis GW, Beaver HA, Johns $\mathrm{K}$, et al. Basic and Clinical Science, Section 2: Fundamentals and Principles of Ophthalmology. San Francisco: American Academy of Ophthalmology: p. 170-1.

2. Skuta GL, Cantor LB, Weiss JS, Regillo C, Holekamp N, Johnson MW. Basic and Clinical Science Course, Section 12: Retina and Vitreous. San Francisco: American Academy of Ophthalmology, 2008: p. 8

3. Skuta GL, Cantor LB, Weiss JS, Moorthy RS, Davis J, Foster CS, et al. Basic and Clinical Science Course, Section 9: Intraocular Inflammation and Uveitis. San Francisco: American Academy of Ophthalmology, 2008: p. 103.

4. Skuta GL, Cantor LB, Weiss JS, Brobow JC, Blecher MH, Glasser DB, et al. Basic and Clinical Science Course, Section 11: Lens and Cataract. San Francisco: American Academy of Ophthalmology, 2008: p. 43

5. Skuta GL, Cantor LB, Weiss JS, Brobow JC, Blecher MH, Glasser DB, et al. Basic and Clinical Science Course, Section 11: Lens and Cataract. San Francisco: American Academy of Ophthalmology, 2008: p. 104

6. Skuta GL, Cantor LB, Weiss IS, Regillo C, Holekamp N, Johnson MW, et al. Basic and Clinical Science Course, Section 12: Retina and Vitreous. San Francisco: American Academy of Ophthalmology, 2008: p. 293.

7. Oetting TA. Basic Principles of Ophthalmic Surgery, 2nd edition. San Francisco: American Academy of Ophthalmology, 2011: p. 216

8. Skuta GL, Cantor LB, Weiss IS, Sutphin JE, Dana MR, Florakis GJ, et al. Basic and Clinical Science Course, Section 8: External Disease and Cornea. San Francisco: American Academy of Ophthalmology, 2008: p. 385

9. Skuta GL, Cantor LB, Weiss IS, Sutphin JE, Dana MR, Florakis GJ, et al. Basic and Clinical Science Course, Section 8: External Disease and Cornea. San Francisco: American Academy Ophthalmology, 2008: p. 31

10. Skuta GL, Cantor LB, Weiss IS, Sutphin JE, Dana MR, Florakis GJ, et al. Basic and Clinical Science Course, Section 8: External Disease and Cornea. San Francisco: American Academy of Ophthalmology, 2008: p. 453-60

11. Skuta GL, Cantor LB, Weiss IS, Cioffi GA, Durcan FJ, Girkin CA, et al. Basic and Clinical Science Course, Section 10: Glaucoma. San Francisco: American Academy of Ophthalmology, 2008: p. 3. 